\title{
Modelling lactation curves for fat-to-protein ratio of milk in the first three lactations of Polish Holstein-Friesian cows
}

\author{
A. Satola" \\ Department of Genetics, Animal Breeding and Ethology, Faculty of Animal Science, University of Agriculture in Krakow, \\ Krakow, Poland
}

(Submitted 14 October 2020, Accepted 9 March 2021, Published 30 April 2021)

\author{
See: http://creativecommons.org/licenses/by/4.0/za \\ Condition of use: The user may copy, distribute, transmit and adapt the work, but must recognise the authors and the South African \\ Journal of Animal Science.
}

\begin{abstract}
Among milk traits, fat-to-protein ratio (FPR) is considered a potential measure of a cow's energy status and is one of the selection criteria necessary to improve metabolic stability. Further genetic analyses require an appropriate model that describes the pattern of FPR changes throughout lactation. The objective of the study was to examine five mathematical functions to describe the lactation curve for FPR in the first three lactations of Polish Holstein-Friesians. The dataset contained FPR records for 5690 cows in the first lactation, 4081 cows in the second, and 2636 cows in the third lactation based on 48908, 34706, and 22097 test-day (TD) records, respectively. Using the MIXED procedure of SAS statistical analytics software, ten linear models (five with fixed effects only, and five with the additional random effect of cow) were fitted to the TD records. The goodness of fit was tested with Akaike's information criterion, residual variances and the correlation coefficient between the actual and estimated values. The model proposed by Ali and Schaeffer (1987) had the best fit to FPR in the first three parities, and the model of Wilmink (1987) provided the worst fit. The correlation coefficient between the actual and the estimated values of FPR was higher for models that included the random cow effect compared with models without this effect.
\end{abstract}

Keywords: dairy cows, goodness of fit, model comparison, model evaluation

${ }^{\#}$ Corresponding author: alicja.satola@urk.edu.pl

\section{Introduction}

Modelling lactation curves for dairy cows has been under development from the first half of the twentieth century (Brody et al., 1924; Grossman \& Koops, 1988; Tozer \& Huffaker, 1999; Tekerli et al., 2000; Macciotta et al., 2005; Silvestre et al., 2006; Torshizi et al., 2011). The suitability of mathematical functions for modelling lactation curves for other species (dairy goats, sheep, beef cows) was also investigated (Hohenboken et al., 1992; Carta et al., 1995; Groenewald et al., 1995). Initially, the lactation curve models were prepared only for milk yield to explain the main features of the milk production pattern and to imitate the functioning of the mammary gland during pregnancy and lactation (Neal \& Thornley, 1983; Macciotta et al., 2005; Silvestre et al., 2006). Lactation curves provided information about dairy cattle production, which could be used for herd management. Lactation curves were also used for modelling fixed and random regressions in test-day models (Ptak \& Schaeffer, 1993; Jamrozik \& Schaeffer, 1997).

Calculation of genetic parameters requires appropriate models. Hence various mathematical functions were investigated to describe the shape of the lactation curve. The most popular functions were those of Wood (1967), Ali and Schaeffer (1987), and Wilmink (1987). Then researchers began to use more general mathematical functions such as splines and Legendre polynomials (White et al., 1999; Schaeffer, 2004; Macciotta et al., 2005; Silvestre et al., 2005; Silvestre et al., 2006). Higher-order Legendre polynomials were required to fit the lactation curve correctly. Splines seemed to be a good replacement for Legendre polynomials because of their flexibility in fitting lactation curves. Problems occurred with choosing an optimal number and placement of knots (Silvestre et al., 2005; Bohmanova et al., 2008; Macciotta et al., 2010).

In the past, selection concentrated on high milk production. Genetic improvement of milk traits led to a deterioration of health and fertility. Therefore, new traits such as conformation, fertility, and survival were incorporated into selection indices in many countries. Recently researchers have concentrated on traits connected with the energy balance of cows. Cows affected by negative energy balance, especially during 
early lactation, are more prone to fertility and health problems such as mastitis, lameness, digestive and locomotive problems, and ketosis (Goff \& Horst, 1997, Collard et al., 2000; Negussie et al., 2013). Measuring cow energy balance was too expensive. Hence other cow energy balance indicators were investigated (de Vries \& Veerkamp, 2000; Reist et al., 2002; Friggens et al., 2007; Buttchereit et al., 2011). The fat-to-protein ratio of milk seemed to be an appropriate one. Moreover, it is readily available because the milk yield and its components (e.g., fat and protein percentages) are measured routinely in many countries, particularly in Poland.

Relatively few research articles have investigated the modelling of FPR during lactation (Buttchereit et al., 2010; Hossein-Zadeh, 2016; Mokhtari et al., 2017). Models that have been investigated for yields of milk, fat, and protein include third and fourth-order Legendre polynomials, Brody, Dhanoa, Sikka (parabolic), Nelder (inverse polynomial), Rook, Dijkstra, and Narushin-Takma among others (Ali \& Schaeffer, 1987); Buttchereit et al., 2010; Hossein-Zadeh, 2016; Mokhtari et al., 2017; Wilmink, 1987). To the best of the author's knowledge, no research has ever addressed the modelling of lactation curves for FPR in the population of Polish Holstein-Friesian cows. However, some authors had investigated mathematical functions for modelling lactation curves for milk, fat and protein yield of Polish Holstein-Friesians (Frącz \& Ptak, 2003; Ptak et al., 2004; Strabel, 2004; Strabel et al., 2005; Otwinowska-Mindur et al., 2013).

The aim of this study was to examine several linear models that described FPR in the first three lactations of Polish Holstein-Friesian cows. Fixed regressions were modelled using five functions, namely Ali and Schaeffer, Wilmink, Guo and Swalve, Legendre polynomials of the third and fourth orders (Ali \& Schaeffer, 1987; Wilmink, 1987; Guo \& Swalve, 1995; Brotherstone et al., 2000).

\section{Materials and Methods}

Records were provided by commercial dairy farms of test-day (TD) milk yield, fat and protein percentages in the first three lactations of Polish Holstein-Friesian cows that calved from 2000 to 2012 in nine herds. Daily FPR was calculated as the ratio of TD fat percentage to protein percentage. Records from days in milk (DIM) before 5 days and after 305 days were discarded. Daily fat and protein percentages ranged from $1 \%$ to $9 \%$. Only cows with at least four TD records per lactation were included in the dataset (4 11 TD records for individual cows per lactation). After those constraints had been applied, there were 105711 TD records of 6716 cows in the dataset. Two seasons of calving were created, namely April to September and October to March. These calving age classes (in months) were defined: 20 - 24, 25- 26, 27 $28,29-30,31$ - 45 in the first lactation; $31-38,39-41,42-44,45-65$ in second lactation; and $43-51,52$ - 55, $56-74$ in third lactation.

Two types of model were used to predict the FPR value. Type I included the fixed effects only, whereas type II included the random effect of the cow.

Type I models were as follows:

$$
y_{i j k l m}=\mu+T D_{i}+A C_{j}+S C_{k}+H_{l}+\sum_{n=1}^{p} b_{n} x_{i j k l m n}(t)+e_{i j k l m}
$$

where: $y_{i j k l m}$ is $m$-th observation of the FPR in the $i$-th test day, $j$-th age at calving class, $k$-th season of calving class and $l$-th herd,

$\mu$ is the overall mean,

$T D_{i}$ is the fixed effect of the $i$-th test day $(i=1, \ldots, 661$ in the first lactation, $i=1, \ldots, 640$ in the second lactation and $i=1, \ldots, 613$ in the third lactation),

$A C_{j}$ is the fixed effect of the $j$-th age at calving class $(j=1,2,3,4,5$ in the first lactation, $j=1,2,3,4$ in the second lactation and $j=1,2,3$ in the third lactation),

$S C_{k}$ is the fixed effect of the $k$-th season of calving class $(k=1,2)$,

$H_{l}$ is the fixed effect of $l$-th herd $(I=1, \ldots, 9)$,

$b_{n}$ is the fixed regression coefficients on the function term of lactation day $t$, and

$e_{i j k l m}$ is random residual effect.

Type II models were as follows:

$$
y_{i j k l m n}=\mu+T D_{i}+A C_{j}+S C_{k}+H_{l}+\sum_{p=1}^{r} b_{p} x_{i j k l m n p}(t)+\operatorname{cow}_{m}+e_{i j k l m n}
$$

where: $y_{i j k l m n}$ is $n$-th observation of the FPR in the $i$-th test day, $j$-th age at calving class, $k$-th season of calving class, $l$-th herd and $m$-th cow,

$T D_{i}, A C_{j}, S C_{k}, H_{l}$ is defined as above, 
$b_{p}$ is the fixed regression coefficients on the function term of lactation day $t$,

cow $_{m}$ is the random effect of the $m$-th cow $(m=1, \ldots, 5690$ in the first lactation, $m=1, \ldots, 4081$ in the second lactation and $m=1, \ldots, 2636$ in the third lactation), and

$e_{i j k l m n}$ is random residual effect.

The fixed regression was modelled by five functions on DIM:

Ali and Schaeffer (1987) curve (ALI):

$$
y=b_{0}+b_{1} \frac{t}{305}+b_{2}\left(\frac{t}{305}\right)^{2}+b_{3} \ln \left(\frac{305}{t}\right)+b_{4} \ln ^{2}\left(\frac{305}{t}\right), t=D I M
$$

Wilmink (1987) curve (WIL):

$$
y=b_{0}+b_{1} t+b_{2} e^{-0.05 t}, t=D I M
$$

Guo and Swalve (1995) curve (GUO):

$$
y=b_{0}+b_{1} \sqrt{t}+b_{2} \ln t, t=D I M
$$

Legendre polynomial of third order (LEG3):

$$
y=b_{0}+b_{1} \sqrt{3} x+b_{2} \frac{\sqrt{5}}{2}\left(3 x^{2}-1\right)+b_{3} \frac{\sqrt{7}}{2}\left(5 x^{3}-3 x\right)
$$

and Legendre polynomial of fourth order (LEG4):

$$
y=b_{0}+b_{1} \sqrt{3} x+b_{2} \frac{\sqrt{5}}{2}\left(3 x^{2}-1\right)+b_{3} \frac{\sqrt{7}}{2}\left(5 x^{3}-3 x\right)+b_{4} \cdot \frac{3}{8}\left(35 x^{4}-30 x^{2}+3\right)
$$

where: $x=2 \frac{t-t_{\min }}{t_{\max }-t_{\min }}, t=D I M, t_{\min }=5, t_{\max }=305$.

Both models were analysed with the MIXED procedure of SAS and REML estimation method (SAS Institute, 2008). Akaike's information criterion (Akaike, 1974) was used to evaluate the goodness of fit of the models of FPR prediction:

$$
A I C=-2 \ln L+2 k
$$

where: $k$ is the number of estimated parameters in the model and

$\ln L$ is the logarithm of the restricted maximum likelihood function.

Competing models can be ranked according to their AIC. The model that minimized AIC should be applied, but with similar values of AIC, the simpler model should be selected. The estimate of the correlation (R) between real and predicted values was used as an additional criterion (Guo \& Swalve, 1995). A further criterion of goodness of fit was the residual variance.

\section{Results and Discussion}

Cows with eight or more TD records comprised $90 \%, 87 \%$ and $85 \%$ in the first, second and third lactations, respectively. In each of the first three lactations, the highest percentage of cows had nine TD records $(60 \%, 57 \%$, and $52 \%$ in first, second, and third lactations, respectively). The mean TD milk yield was lowest in the first lactation (26.70) and highest in the third lactation (31.15), whereas the mean test-day FPR remained at the same level in all three lactations $(0.15-0.16)$ (Table 2). Tables 1 and 2 show statistics of the dataset used in the analyses. 
Table 1 Number of cows and test-day records in the first three lactations

\begin{tabular}{lcc}
\hline Lactation & Number of cows & Number of records \\
\hline 1 & 5690 & 48908 \\
2 & 4081 & 34706 \\
3 & 2636 & 22097 \\
\hline
\end{tabular}

Table 2 Mean and standard deviation of fat-to-protein ratio, fat content, protein content and milk yield in the first three lactations

\begin{tabular}{|c|c|c|c|c|c|c|}
\hline \multirow{2}{*}{ Trait } & \multicolumn{2}{|c|}{ Lactation 1} & \multicolumn{2}{|c|}{ Lactation 2} & \multicolumn{2}{|c|}{ Lactation 3} \\
\hline & Mean & SD & Mean & SD & Mean & SD \\
\hline FPR & 1.15 & 0.21 & 1.15 & 0.21 & 1.16 & 0.23 \\
\hline Fat, \% & 3.86 & 0.77 & 3.90 & 0.80 & 3.92 & 0.83 \\
\hline Protein, \% & 3.37 & 0.34 & 3.40 & 0.38 & 3.39 & 0.39 \\
\hline Milk, kg & 26.70 & 7.31 & 30.53 & 9.73 & 31.15 & 10.32 \\
\hline
\end{tabular}

FPR: fat-to-protein ratio

The average values of milk yield and FPR were calculated for each day of the first three lactations and are presented in Figure 1 and Figure 2, respectively. The pattern of changes of milk yield are typical in shape with peak milk yield at around 35 DIM. Average milk yield for a particular DIM was lower in the first lactation than in the second and third lactations and the first lactation was more persistent than later lactations. The FPR curves were the mirror image of the milk yield curves, with highest values at the beginning of the lactation. The values decreased to 65 DIM and stabilized at about 1.15 to the end of lactation.

The models that included the random effect of the cow showed a better data fit than those with fixed effects only. The coefficients of correlation between the real and estimated values for FPR were higher for models including the random effect of the cow $(0.67-0.76)$ than for models with fixed effects only $(0.47$ 0.52). The residual variances for models including the random effect of the cow were slightly lower $(0.02$ $0.03)$ than in the case of models with fixed effects only $(0.03-0.04)$. Tables 3 and 4 present the evaluation criteria for the type I and type II models.

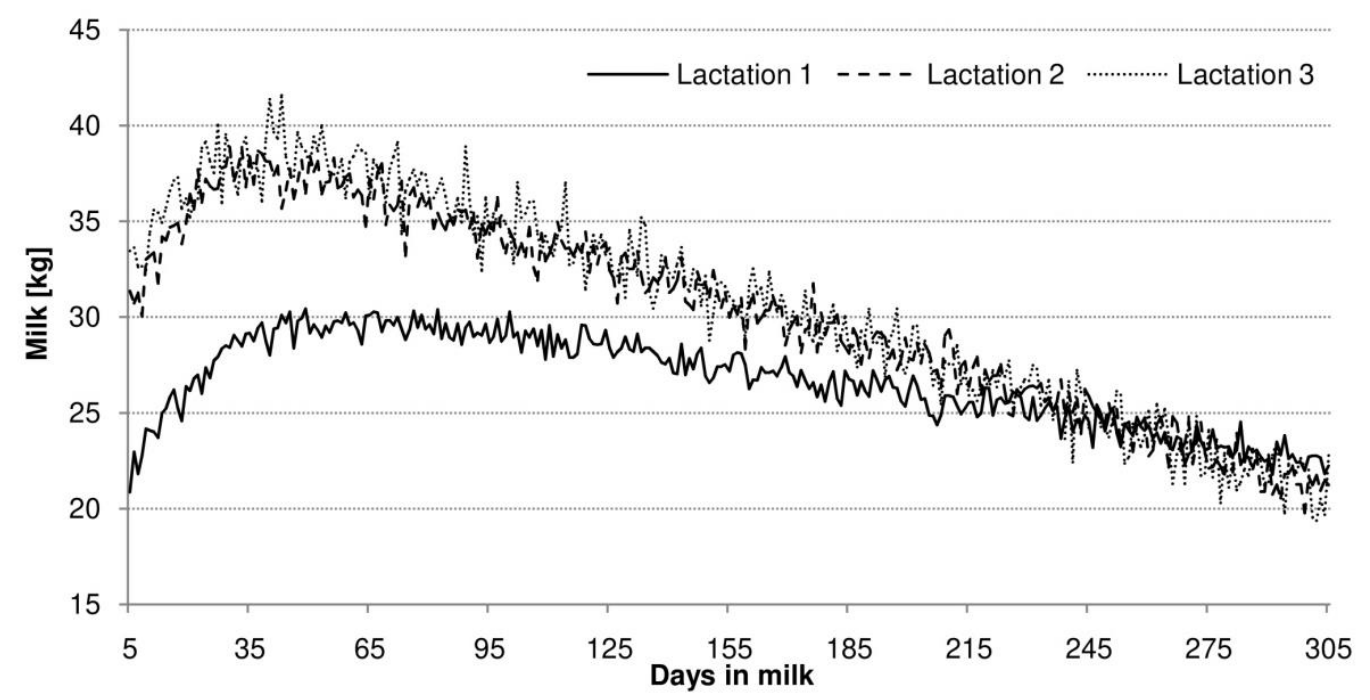

Figure 1 Average lactation curves of milk yield $(\mathrm{kg})$ in the first three lactations 


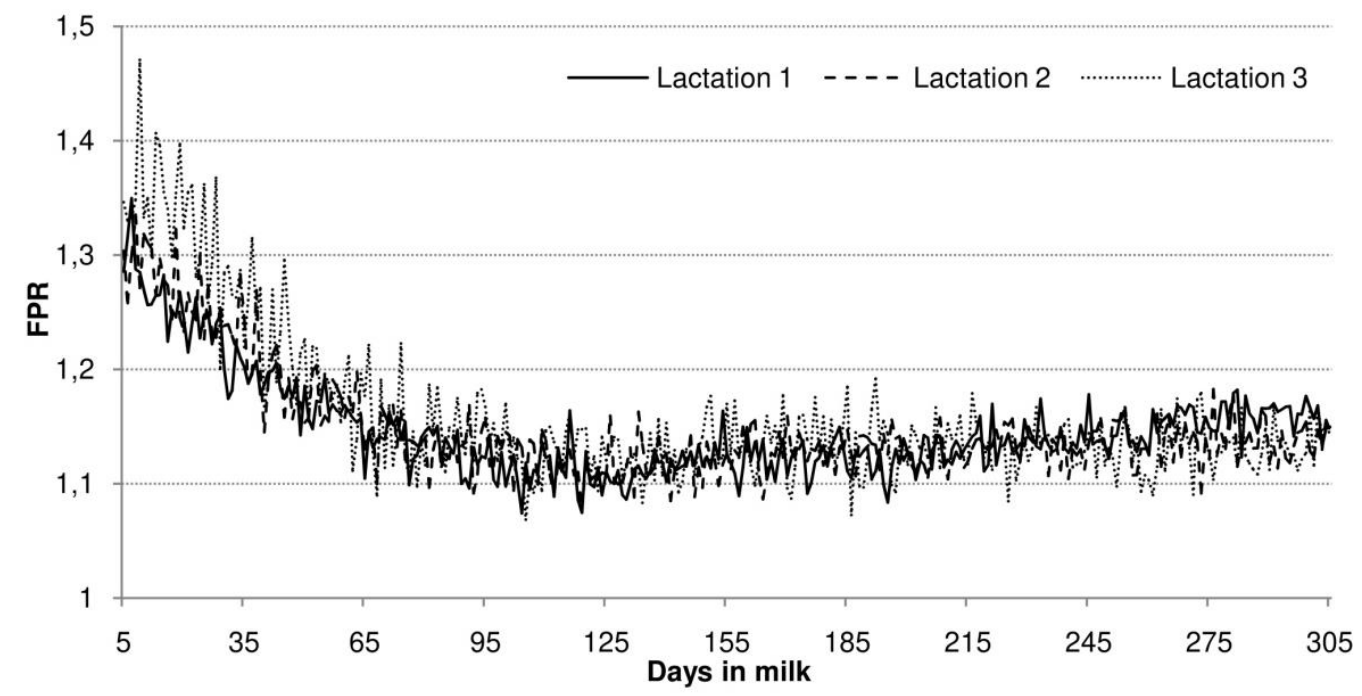

Figure 2 Average lactation curves of fat-to-protein ratio in the first three lactations FPR: fat-to-protein ratio

The goodness of fit of lactation models was analysed using AIC (Table 3 and Table 4). Of the models with fixed effects only, the ALI model performed better than the others, regardless of the number of lactations. The LEG4 model was nearly as good as the ALI model. The WIL model provided the worst fit to FPR in each of the first three lactations. Among the models with the added random effect of the cow, the ALI model fitted better than the other models, whereas the WIL model gave the worst fit.

Table 3 Akaike's information criterion, correlation between real and estimated values $(r)$ and the residual variance for fat-to-protein ratio using the fixed regression model with days in milk functions

\begin{tabular}{lllll}
\hline Lactation & Model & AIC & $r$ & var e \\
\hline \multirow{4}{*}{1} & ALI & -27613.1 & 0.52 & 0.03133 \\
& WIL & -27352.3 & 0.51 & 0.03150 \\
& GUO & -27475.6 & 0.51 & 0.03143 \\
& LEG3 & -27581.4 & 0.52 & 0.03135 \\
& LEG4 & -27598.5 & 0.52 & 0.03133 \\
\hline \multirow{4}{*}{ ALI } & -14109.9 & 0.48 & 0.03617 \\
& WIL & -13963.6 & 0.47 & 0.03632 \\
& GUO & -14006.3 & 0.48 & 0.03629 \\
& LEG3 & -14081.8 & 0.48 & 0.03619 \\
& LEG4 & -14095.5 & 0.48 & 0.03617 \\
\hline ALI & -4807.0 & 0.49 & 0.04264 \\
& WIL & -4682.3 & 0.49 & 0.04289 \\
& GUO & -4693.8 & 0.49 & 0.04288 \\
& LEG3 & -4737.2 & 0.49 & 0.04277 \\
& LEG4 & -4784.9 & 0.49 & 0.04265
\end{tabular}

AIC: Akaike's information criterion; DIM: days in milk; ALI: Ali \& Schaeffer; WIL: Wilmink; GUO: Guo \& Swalve; LEG3: Legendre polynomials of the third order; LEG4: Legendre polynomials of the fourth order; var e: residual variance 
Table 4 Akaike's information criterion, correlation between real and estimated values $(R)$ and the residual variance for fat-to-protein ratio using the mixed model with random effect of cow and fixed regression days in milk functions

\begin{tabular}{lllll}
\hline Lactation & Model & AIC & R & var e \\
\hline \multirow{4}{*}{1} & ALI & -35060.6 & 0.76 & 0.02263 \\
& WIL & -34695.4 & 0.75 & 0.02283 \\
& GUO & -34859.7 & 0.75 & 0.02274 \\
& LEG3 & -35022.4 & 0.76 & 0.02265 \\
& LEG4 & -35047.6 & 0.76 & 0.02263 \\
\hline \multirow{4}{*}{ ALI } & -19294.0 & 0.67 & 0.02614 \\
& WIL & -19092.5 & 0.67 & 0.02632 \\
& GUO & -19145.9 & 0.67 & 0.02628 \\
& LEG3 & -19253.6 & 0.67 & 0.02617 \\
& LEG4 & -19279.8 & 0.67 & 0.02614 \\
\hline ALI & -7094.6 & 0.69 & 0.03299 \\
& WIL & -6947.7 & 0.69 & 0.03324 \\
& GUO & -6962.2 & 0.69 & 0.03322 \\
& LEG3 & -7006.7 & 0.69 & 0.03313 \\
& LEG4 & -7074.0 & 0.69 & 0.03299
\end{tabular}

AIC: Akaike's information criterion; DIM: days in milk; ALI: Ali \& Schaeffer; WIL: Wilmink; GUO: Guo \& Swalve; LEG3: Legendre polynomials of the third order; LEG4: Legendre polynomials of the fourth order; var e: residual variance

Type I and type II models had nearly the same curve parameters, so only the results of type I models are presented. Figures 3, 4, and 5 show lactation curves of FPR modelled with various functions in the first, second and third lactations, respectively. In the first lactation the LEG3 and LEG4 curves were identical to certain extent. The ALI curve, which fitted better to the data than the other curves, estimated slightly higher values at the beginning of the lactation (to about 20 DIM) than the LEG3 and LEG4 and lower values than the Legendre polynomials between 20 and 95 DIM. The ALI model and the LEG3 and LEG4 polynomials are nearly the same in the remaining part of lactation. Differences between the values of FPR for a particular DIM estimated by the ALI and LEG4 models, did not exceed 0.018 , whereas the differences between the ALI and LEG3 models did not exceed 0.015 .

In type I models there were some differences between the two groups of curves: ALI, LEG3 and LEG4 versus WIL and GUO. According to AIC, the WIL and GUO curves showed a worse fit to the data than those from the first group (Table 3) and estimated higher FPR values at the beginning of the first lactation (1.45 and 1.48, respectively) compared with the ALI, LEG3 and LEG4 curves (about 1.39). Also, from 70 DIM nearly to the end of lactation (275 DIM), the WIL model estimated higher values compared with the other curves.

In the first lactation ALI, LEG3 and LEG4 resembled a U-shaped curve with the minimum (1.21) at about 140 DIM, whereas the values estimated by WIL and GUO after decrease at the beginning of lactation (to 65 DIM) stabilized at the level of $1.23-1.24$ to the end of lactation.

Differences between the estimates of FPR for a particular DIM from different models in the second lactation are smaller than in the first lactation, especially in the middle part. The highest values of FPR estimated by all curves were at the beginning of lactation (1.39 - 1.48), then the values decreased to 65 DIM and oscillated between 1.22 and 1.25 until the end of the lactation. In the third lactation, as in the second, the values estimated by the models for a particular DIM differed slightly. However, the values estimated at the beginning of the third lactation (1.55 - 1.66) were higher than those at the beginning of the first and second lactations. After $80 \mathrm{DIM}$, the FPR values stabilized at $1.33-1.36$ 


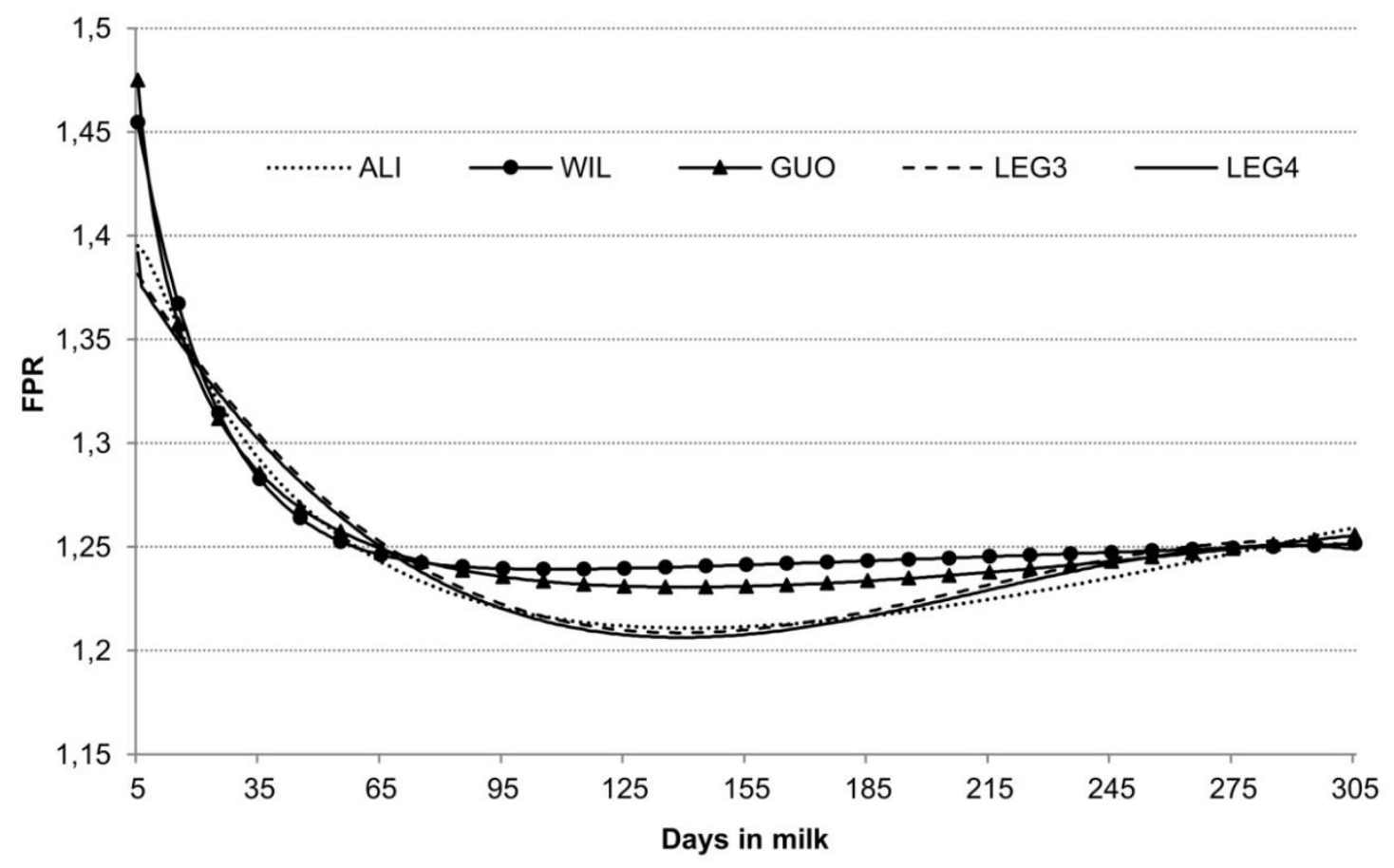

Figure 3 Lactation curves for fat-to-protein ratio of cows in the first lactation modelled with the Ali \& Schaeffer, Wilmink, and Guo \& Swalve functions, and Legendre polynomials of the third and fourth order applied to the type I model

FPR: fat to protein ratio; ALI: Ali \& Schaeffer; WIL: Wilmink; GUO: Guo \& Swalve; LEG3: Legendre polynomials of the third order; LEG4: Legendre polynomials of the fourth order

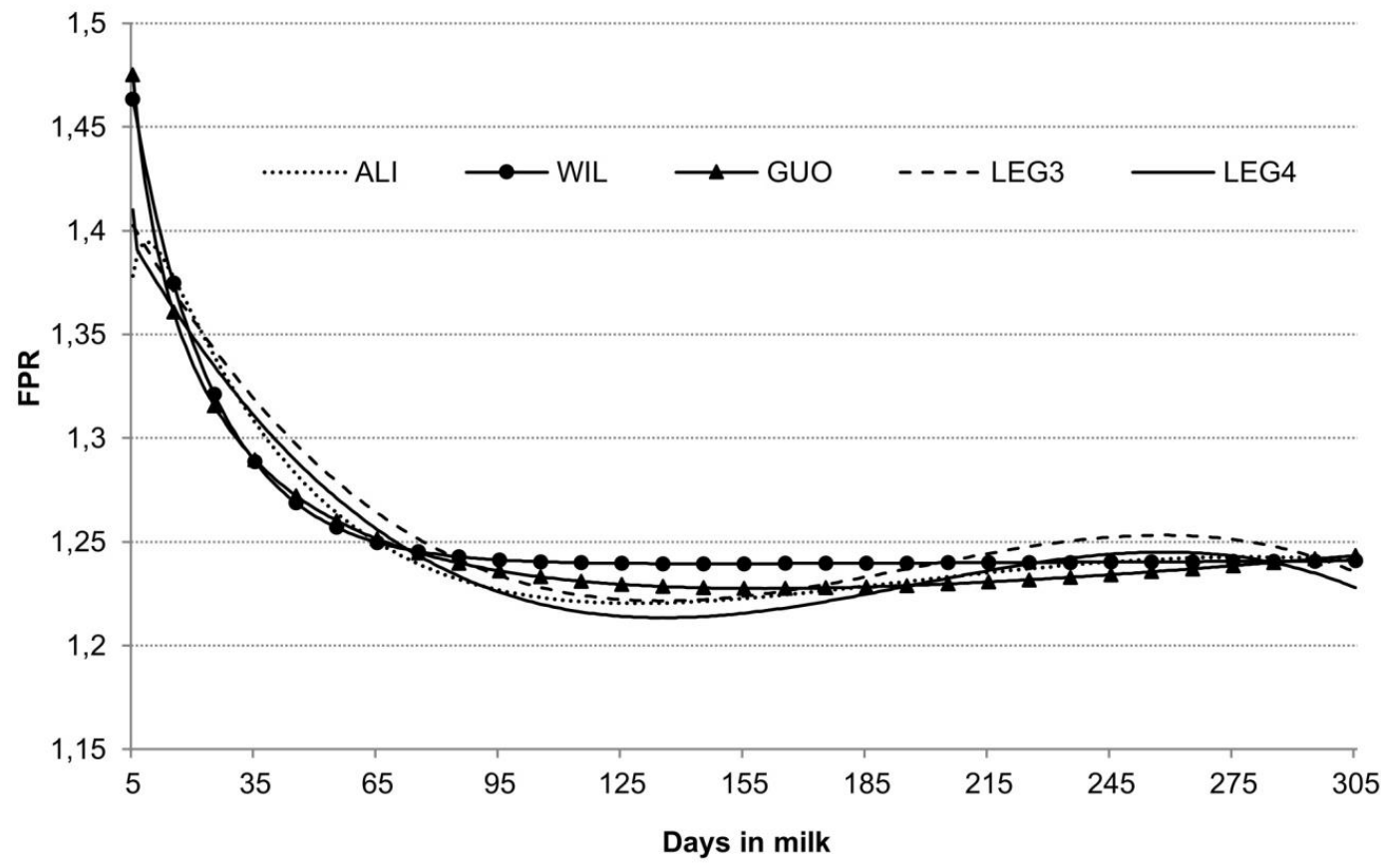

Figure 4 Lactation curves for fat-to-protein ratio of cows in the second lactation modelled with the Ali \& Schaeffer, Wilmink, and Guo \& Swalve functions, and Legendre polynomials of the third and fourth order applied to the type I model

FPR: fat to protein ratio; ALI: Ali \& Schaeffer; WIL: Wilmink; GUO: Guo \& Swalve; LEG3: Legendre polynomials of the third order; LEG4: Legendre polynomials of the fourth order 


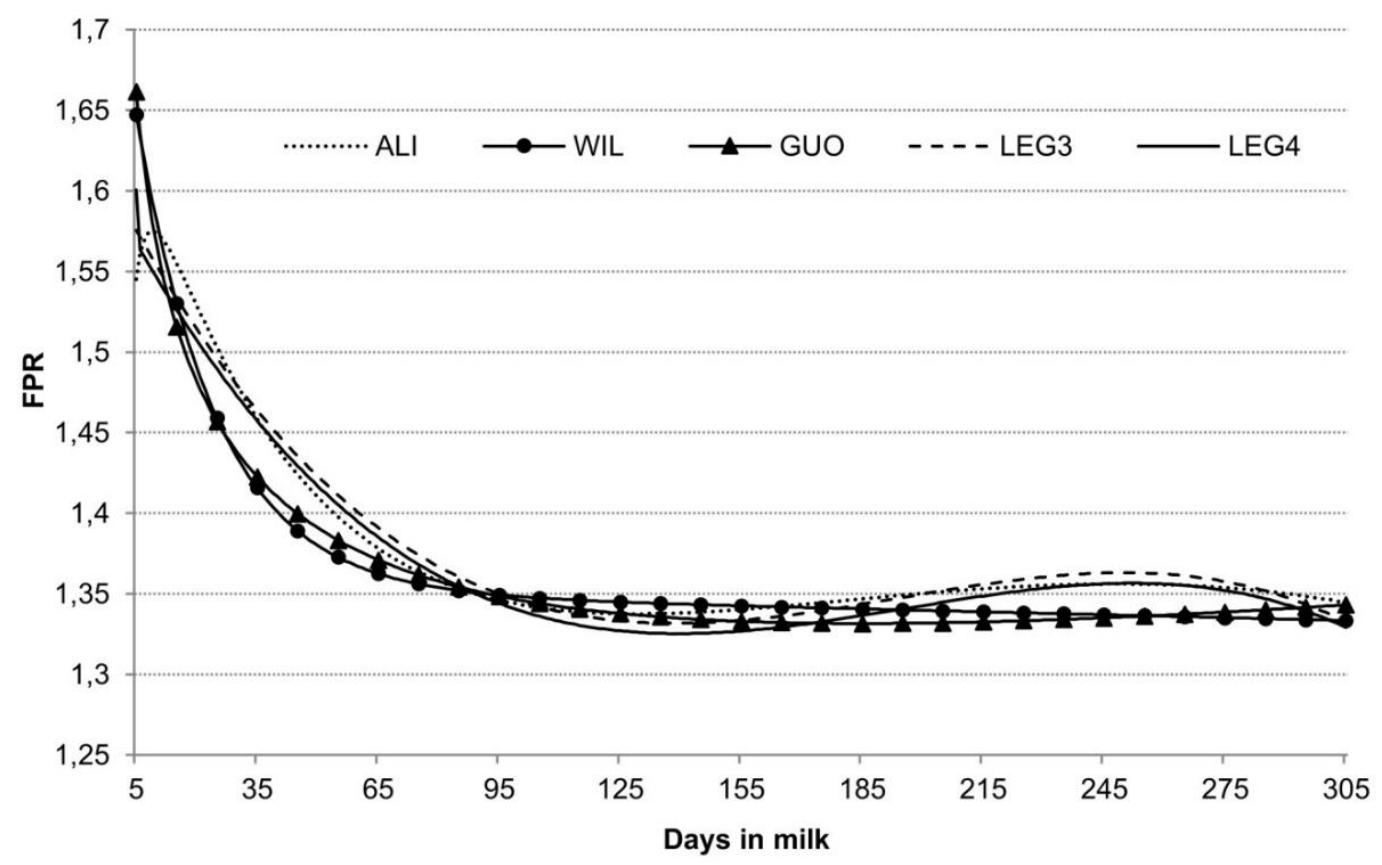

Figure 5 Lactation curves for fat-to-protein ratio of cows in the third lactation modelled with the Ali \& Schaeffer, Wilmink, and Guo \& Swalve functions, and Legendre polynomials of the third and fourth order applied to the type I model

FPR: fat to protein ratio; ALI: Ali \& Schaeffer; WIL: Wilmink; GUO: Guo \& Swalve; LEG3: Legendre polynomials of the third order; LEG4: Legendre polynomials of the fourth order

The minimum and maximum FPR predicted by type I models on the DIM on which they were reached, were shown in Table 5. These values were compared with the average values of observed FPR calculated for every DIM of the first, second and third lactations. In the first lactation all models over-predicted the minimum FPR and DIM of minimum FPR. Maximum FPR in the first lactation was over-predicted, too. ALI, LEG3 and LEG4 provide closer prediction of FPR than WIL and GUO models. In the second and third lactations, minima FPR and the days that they were reached were also over-predicted. The DIM with maximum FPR and maximum FPR in the second lactation were best estimated by the ALI model. In the third lactation, all models over-predicted the maximum FPR, and only the ALI model predicted DIM of maximum FPR precisely.

Models with the random effect of cow had a better fit to the data than those with fixed effects only, as expected. The estimated correlation between the observed values and those estimated by various models oscillated between 0.67 and 0.76 for models with random effect of cow and between 0.47 and 0.52 for models with fixed effects only. Buttchereit et al. (2010), who modelled FPR for German cows, also obtained a higher estimated correlation for random regression models $(0.86-0.88)$ than in fixed regression models (0.52 - 0.59). These authors tested the ALI, WIL, GUO, LEG3, and LEG4 models and obtained higher values of correlation coefficient than those presented in this study owing to the profile of data used for calculation. Their FPR data represented weekly measurements, whereas the current FPR data came from TD records. Buttchereit et al. (2010) reported that the ALI model was the most suitable for FPR and LEG4 modelled the lactation curve for FPR almost as well as the ALI model. It is in conformity with this study's results.

The lactation curves modelled with the ALI function using type I models were practically the same in the first and second lactations, with values about 1.4 at the beginning of the lactation, decreasing to 65 DIM and remaining at the level $1.21-1.25$ to the end of lactation. Similarly, ALI curves for FPR in the first and second lactations presented by Buttchereit et al. (2010), with values 1.4 at the beginning of the first and second lactations, decreased to 80 DIM and stabilized at $1.05-1.10$ to the end of lactation. The values of FPR in the third lactation of Polish Holstein-Friesians modelled by the ALI curve (1.57 at the beginning and about 1.35 from 80 DIM to the end of lactation) were higher than in the first and second lactations. Buttchereit et al. (2010) also obtained higher values in the third lactation, but the values stabilized at a lower level (1.15) than in Polish cows. 
Table 5 Minimum and maximum fat-to-protein ratios and days in milk of minimum or maximum ratios predicted by type I models with fixed regression days in milk functions

\begin{tabular}{|c|c|c|c|c|c|}
\hline \multirow{2}{*}{ Lactation } & \multirow{2}{*}{ Model } & \multicolumn{2}{|c|}{ MIN } & \multicolumn{2}{|c|}{ MAX } \\
\hline & & DIM & FPR & DIM & FPR \\
\hline \multirow{6}{*}{1} & ALI & 141 & 1.21 & 5 & 1.40 \\
\hline & WIL & 107 & 1.24 & 5 & 1.45 \\
\hline & GUO & 140 & 1.23 & 5 & 1.48 \\
\hline & LEG3 & 139 & 1.21 & 5 & 1.38 \\
\hline & LEG4 & 139 & 1.21 & 5 & 1.39 \\
\hline & Observed & 104 & 1.07 & 7 & 1.35 \\
\hline \multirow{6}{*}{2} & ALI & 128 & 1.22 & 8 & 1.39 \\
\hline & WIL & 144 & 1.24 & 5 & 1.46 \\
\hline & GUO & 160 & 1.23 & 5 & 1.48 \\
\hline & LEG3 & 135 & 1.22 & 5 & 1.40 \\
\hline & LEG4 & 135 & 1.21 & 5 & 1.41 \\
\hline & Observed & 119 & 1.08 & 8 & 1.34 \\
\hline \multirow{6}{*}{3} & ALI & 129 & 1.34 & 9 & 1.57 \\
\hline & WIL & 305 & 1.33 & 5 & 1.65 \\
\hline & GUO & 185 & 1.33 & 5 & 1.66 \\
\hline & LEG3 & 139 & 1.33 & 5 & 1.57 \\
\hline & LEG4 & 140 & 1.32 & 5 & 1.60 \\
\hline & Observed & 105 & 1.07 & 9 & 1.47 \\
\hline
\end{tabular}

MIN: minimum; MAX: maximum; FPR: fat to protein ratio; DIM: days in milk; ALI: Ali \& Schaeffer; WIL: Wilmink; GUO: Guo \& Swalve; LEG3: Legendre polynomials of the third order; LEG4: Legendre polynomials of the fourth order

The FPR was highest at the beginning of the lactation when the metabolic load was greatest. The highest value of FPR in early lactation could be attributed to the negative energy balance and thus tissue mobilization associated with the stress of calving and peak milk production (Mokhtari et al., 2017). In early lactation, cows mobilize fat from body reserves to compensate for the deficiency of energy (Loker et al., 2012). As a result, fat synthesis in the udder is increased (Buttchereit et al., 2010). Inadequate intake of fermentable carbohydrates leads to an insufficient protein synthesis by ruminal bacteria and decrease of protein content in milk (Buttchereit et al., 2010). The consequence of these processes is an increase in FPR. Therefore, the FPR in milk could be used as a practical criterion to identify cows that are able to overcome metabolic issues during early lactation. Negussie et al. (2013) explained that the increase of FPR after reaching the minimum could be connected to increasing energy requirements of pregnant cows to support milk production and foetal growth.

The curves modelled by LEG3 and LEG4 using type I models were almost the same (Figures 3, 4, 5) and nearly as good as the ALI curve (Table 3). The shapes of WIL and GUO curves were slightly different from the ALI, LEG3 and LEG4 curves and showed an inferior fit (Table 3). Similar results were obtained by Buttchereit et al. (2010).

On the other hand, Hossein-Zadeh (2016) examined seven non-linear equations to describe the lactation curve for FPR, namely Brody, Wood, Dhanoa, Sikka, Nelder, Rook, and Dijkstra (Brody et al., 1923; Sikka, 1950; Nelder, 1966; Wood, 1967; Dhanoa, 1981; Rook et al., 1993; Dijkstra et al., 1997). The parameters in these models described the course of lactation curves. As an example, in the model proposed by Wood (1967), which has been used widely to study lactation curves, there are three parameters, namely the scaling factor, which represents yield at the beginning of lactation, the inclining slope parameter up to peak yield, and the declining slope parameter. Such an interpretation cannot be applied to the parameters of the ALI or Legendre polynomials. Taking into account the AIC and the Bayesian information criterion (BIC), 
Hossein-Zadeh (2016) concluded that the Dijkstra equation provided the best fit of FPR in the first three parities of Iranian Holsteins and the Nelder model provided the worst fit. However, the adjusted coefficient of determination and root mean square error were practically the same for these models. The authors observed FPR to be highest at the beginning of lactation, and subsequently to decrease rapidly during early lactation (up to about $60 \mathrm{DIM}$ ), which was followed by a slow increase towards the end of lactation. Only the Nelder model was not a U-shaped curve. The values of FPR predicted by this model decreased to the end of lactation. In this study, GUO and WIL curves, which provided the worst fit to the data, did not resemble a Ushaped curve either. After decreasing at the beginning of lactation, the FPR values remained constant to the end of lactation. The values of FPR predicted by various curves for Iranian Holsteins (Hossein-Zadeh, 2016) were lower than those presented in this study: approximately $1.2-1.3$ at the beginning of lactation and 1.0 1.1 in the middle part of lactation. The usefulness of the functions proposed by Hossein-Zadeh (2016) for modelling fixed and random regressions in the test-day model was rather limited because of the nonlinearity of those functions.

Mokhtari et al. (2017) compared the mathematical functions proposed by Wood (1967), Ali and Schaeffer (1987), Wilmink (1987), Rook et al. (1993), Dijkstra et al. (1997), and Narushin and Takma (2003) that described a pattern of changes of FPR in the first lactation of Iranian Holstein cows. Among those models, the Narushin-Takma function showed the best fit to the FPR data according to criteria such as adjusted coefficient of determination, residual standard deviation and the AIC. In opposition to Buttchereit et al. (2010) and the results of this study, Mokhtari et al. (2017) showed that the WIL function fitted better to FPR data compared with the ALI function. The Narushin-Takma function proposed by Mokhtari et al. (2017) is non-linear. Hence it can be used for herd management, but not necessarily for modelling fixed and random regressions.

In this study, the minimum and maximum FPR were over-predicted by all models compared with the average daily FPR calculated directly from the data. In the first and second lactations, the ALI, LEG3 and LEG4 models gave a better prediction of minimum and maximum FPR compared with the GUO and WIL models, especially in the first and second lactations. Similarly, Hossein-Zadeh (2016) reported that the majority of the models analysed by him (Brody, Wood, Nelder, Rook, Dijkstra) over-predicted minimum FPR in the first three lactations.

\section{Conclusions}

Five mathematical functions were tested for modelling the lactation curve for FPR in the first three lactations of Polish Holstein-Friesian cows. Functions that contained five parameters provided a better fit for the FPR data than the functions with fewer parameters. The model based on the ALI curve best fit the FPR records and is therefore recommended for use in modelling fixed regressions in mixed models. It might also be used in herd management to prevent the consequences from cows having a negative energy balance, especially during early lactation. Choosing an appropriate function to describe lactation curve for FPR is the first step in carrying out further genetic analyses and incorporating this trait into breeding programmes as a component of an index for improving energy balance.

\section{Acknowledgements}

This research was financed by the Ministry of Science and Higher Education of the Republic of Poland (SUB. 020012-D015).

\section{Authors' Contributions}

AS was responsible for all facets of the research.

\section{Conflict of Interest Declaration}

The author declares no conflict of interest.

\section{References}

Akaike, H., 1974. A new look at the statistical model identification. IEEE Trans. Autom. Control 19, 716-723.

Ali, T.E., Schaeffer, L.R., 1987. Accounting for covariances among test day milk yields in dairy cows. Can. J. Anim. Sci. 67, 637-644. https://doi.org/10.4141/cjas87-067

Bohmanova, J., Miglior, F., Jamrozik, J., Miszta,I I. \& Sullivan, P.G., 2008. Comparison of random regression models with Legendre polynomials and linear splines for production traits and somatic cell score of Canadian Holstein cows. J. Dairy Sci. 91, 3627-3638. https://doi.org/10.3168/jds.2007-0945

Brody, S., Ragsdale, A.C. \& Turner, C.W., 1923. The rate of decline of milk secretion with the advance of the period of lactation. J. Gen. Physiol. 5, 441-444. DOI: 10.1085/jgp.5.4.441

Brody, S., Turner, C.W. \& Ragsdale, A.C., 1924. The relation between the initial rise and subsequent decline of milk secretion following parturition. J. Gen. Physiol. 6, 541-545. DOI: 10.1085/jgp.6.5.541 
Brotherstone, S., White, I.M.S. \& Meyer, K., 2000. Genetic modelling of dairy milk yield using orthogonal polynomials and parametric curves. Anim. Sci. 70, 407-415. DOI: 10.1017/S1357729800051754

Buttchereit, N., Stamer, E., Junge,, W. \& Thaller G., 2010. Evaluation of five lactation curve models fitted for fat-protein ratio of milk and daily energy balance. J. Dairy Sci. 93, 1702-1712. DOI: 10.3168/jds.2009-2198

Buttchereit, N., Stamer, E., Junge, W. \& Thaller, G., 2011. Short communication: Genetic relationships among daily energy balance, feed intake, body condition score, and fat to protein ratio of milk in dairy cows. J. Dairy Sci. 94, 1586-1591. DOI: $10.3168 /$ jds.2010-3396

Carta, A., Sanna, S.R. \& Casu S., 1995. Estimating lactation curves and seasonal effects for milk, fat and protein in Sarda dairy sheep with a test day model. Livest. Prod. Sci. 44, 37-44. https://doi.org/10.1016/03016226(95)00051-L

Collard, B.L., Boettcher, P.J., Dekkers, J.C.M., Petticlerc, D. \& Schaeffer, L.R., 2000. Relationships between energy balance and health traits of dairy cattle in early lactation. J. Dairy Sci. 83, 2683-2690. DOI: 10.3168/jds.S00220302(00)75162-9

de Vries, M.J. \& Veerkamp, R.F., 2000. [and here. Makes editing syntax very difficult until link is removed] Energy balance of dairy cattle in relation to milk production variables and fertility. J. Dairy Sci. 83, 62-69. DOI: $10.3168 / j d s . S 0022-0302(00) 74856-9$

Dhanoa, M., 1981. A note on an alternative form of the lactation model of Wood. Anim. Sci. 32, 349-351. DOI: $10.1017 /$ S0003356100027276

Dijkstra, J., France, J., Dhanoa, M.S., Maas, J.A., Hanigan, M.D., Rook, A.J. \& Beever, D.E., 1997. A model to describe growth patterns of the mammary gland during pregnancy and lactation. J. Dairy Sci. 80, $2340-2354$. https://doi.org/10.3168/jds.S0022-0302(97)76185-X

Frącz, A. \& Ptak, E., 2003. Prediction of 305-day milk yield of Black and White cows using Ali and Schaeffer lactation curve model (in Polish). Rocz. Nauk. Zoot. Suppl. 17, 349-352.

Friggens, N.C., Ridder, C. \& Løvendahl, P., 2007. On the use of milk composition measures to predict the energy balance of dairy cows. J. Dairy Sci. 90, 5453-5467. DOI: 10.3168/jds.2006-821

Goff, J.P. \& Horst, R.L., 1997. Physiological changes at parturition and their relationship to metabolic disorders. J. Dairy Sci. 80, 1260-1268. DOI: 10.3168/jds.S0022-0302(97)76055-7

Groenewald, P.C.N., Ferreira, A.V., Van der Merwe, H.J. \& Slippers, S.C., 1995. A mathematical model for describing and predicting the lactation curves of Merino ewes. Anim. Sci. 61, 95-101. DOI: 10.1017/S1357729800013564

Grossman, M. \& Koops, W.J., 1988. Multiphasic analysis of lactation curves in dairy cattle. J. Dairy Sci. 71, 1598-1608. https://doi.org/10.3168/jds.S0022-0302(88)79723-4

Guo, Z. \& Swalve, H.H. 1995. Modelling of the lactation curve as a sub-model in the evaluation of test day records. Proc. Interbull Mtg. Prague, International Bull Evaluation Service, Uppsala, Sweden. Interbull Bull. 11, 22-25.

Hohenboken, W.D., Dudley, A. \& Moody, D.E., 1992. A comparison among equations to characterize lactation curves in beef cows. Anim. Prod. 55, 23-28. DOI: 10.1017/S0003356100037223

Hossein-Zadeh, N.G., 2016. Modelling lactation curve for fat to protein ratio in Holstein cows. Anim. Sci. Pap. Rep. 34, 233-246.

Jamrozik, J. \& Schaeffer, L.R., 1997. Estimates of genetic parameters for a test day model with random regressions for yield traits of first-lactation Holsteins. J. Dairy Sci. 80, 762-770. DOI: 10.3168/jds.S0022-0302(97)75996-4

Loker, S., Bastin, C., Miglior, F., Sewalem, A., Schaeffer, L.R., Jamrozi,k J., Ali A. \& Osbornell, V., 2012. Genetic and environmental relationship between body condition score and milk production traits in Canadian Holsteins. J. Dairy Sci. 95, 410-419. DOI: 10.3168/jds.2011-4497

Macciotta, N.P.P., Miglior, F. \& Dimauro, C., 2010. Comparison of parametric orthogonal and spline functions to model individual lactation curves for milk yield in Canadian Holsteins. Ital. J. Anim. Sci. 9, 460-464. https://doi.org/10.4081/ijas.2010.e87

Macciotta, N.P.P., Vicario, D. \& Cappio-Borlino, A., 2005. Detection of different shapes of lactation curve for milk yield in dairy cattle by empirical mathematical models. J. Dairy Sci. 88, 1178-1191. DOI: 10.3168/jds.S00220302(05)72784-3

Mokhtari, M.S., Razmkabir, M., Mohammadi, Y. \& Shahrbabak, M.S., 2017. Comparisons of different models for lactation curves of fat to protein ratio and somatic cell score of Holstein cows in Iran. J. Livest. Sci. Technol. 5, 35-41. DOI: 10.22103/ilst.2017.10494.1198

Narushin, V.G. \& Takma, C., 2003. Sigmoid model for the evaluation of growth and production curves in laying hens. Biosyst. Eng. 84, 343-348. https://doi.org/10.1016/S1537-5110(02)00286-6

Neal, H.D. \& Thornley, J.H.M., 1983. The lactation curve in cattle: A mathematical model of the mammary gland. J. Agric. Sci. 101, 389-400. DOI: 10.1017/S0021859600037710

Negussie, E., Strandén, I. \& Mäntysaari, E.A., 2013. Genetic associations of test-day fat: protein ratio with milk yield, fertility, and udder health traits in Nordic Red cattle. J. Dairy Sci. 96, 1237-1250. DOI: 10.3168/jds.2012-5720

Nelder, J., 1966. Inverse polynomials, a useful group of multi-factor response functions. Biometrics 22, 128-141. https://doi.org/10.2307/2528220

Otwinowska-Mindur, A., Ptak, E., Jagusiak, W. \& Satoła, A., 2013. Modeling lactation curves of Polish Holstein-Friesian cows. Part I: The accuracy of five lactation curve models. J. Anim. Feed Sci. 22, 19-25. DOI: https://doi.org/10.22358/jafs/66012/2013

Ptak, E. \& Schaeffer, L.R., 1993. Use of test day yields for genetic evaluation of dairy sires and cows. Livest. Prod. Sci. 34, 23-34. https://doi.org/10.1016/0301-6226(93)90033-E

Ptak, E., Satoła, A. \& Czaja, H., 2004. Prediction of 305-d lactation milk, fat and protein yields using Legendre polynomials and test-day yields from different parts of lactation. Anim. Sci. Pap. Rep. 22, 173-183. 
Reist, M., Erdin, D., von Euw, D., Tschuemperlin, K., Leuenberger, H., Chilliard, Y., Hammon, H.M. Morel, C., Philipona, C., Zbinden, Y., Kuenzi, N. \& Blum, J.W., 2002. Estimation of energy balance at the individual and herd level using blood and milk traits in high-yielding dairy cows. J. Dairy Sci. 85, 3314-3327. DOI: 10.3168/jds.S00220302(02)74420-2

Rook, A., France, J. \& Dhanoa, M., 1993. On the mathematical description of lactation curves. J. Agric. Sci. 121, 97-102. DOI: $10.1017 / \mathrm{S} 002185960007684 \mathrm{X}$

Schaeffer, L.R., 2004. Application of random regression models in animal breeding. Livest. Prod. Sci. 86, 35-45. DOI: 10.1016/S0301-6226(03)00151-9

Sikka, L., 1950. A study of lactation as affected by heredity and environment. J. Dairy Res. 17, 231-252. DOI: $10.1017 /$ S0022029900005811

Silvestre, A.M., Petim-Batista, M.F. \& Colaco, J., 2005. Genetic parameter estimates of Portuguese dairy cows for milk, fat, and protein using a spline test-day model. J. Dairy Sci. 88, 1225-1230. DOI: 10.3168/jds.S00220302(05)72789-2

Silvestre, A.M., Petim-Batista, F. \& Colaco, J., 2006. The accuracy of seven mathematical functions in modeling dairy cattle lactation curves based on test-day records from varying sample schemes. J. Dairy Sci. 89, 1813-1821. https://doi.org/10.3168/jds.S0022-0302(06)72250-0

Strabel, T., 2004. Age-season lactation curves for production traits of cows calving in Wielkopolska region of Poland. J. Anim. Feed Sci. 13, 405-416. DOI: 10.22358/jafs/67427/2004

Strabel T., Szyda, J., Ptak, E. \& Jamrozik, J., 2005. Comparison of random regression test-day models for Polish Black and White cattle. J. Dairy Sci. 88, 3688-3699. DOI: 10.3168/jds.S0022-0302(05)73055-1

Tekerli, M., Akinci, Z., Dogan, I. \& Akcan, A., 2000. Factors affecting the shape of lactation curves of Holstein cows from the Balikesir province of Turkey. J. Dairy Sci. 83, 1381-1386. DOI: 10.3168/jds.S0022-0302(00)75006-5

Torshizi, M.E., Aslamenejad, A.A., Nassiri, M.R. \& Farhangfar, H., 2011. Comparison and evaluation of mathematical lactation curve functions of Iranian primiparous Holsteins. S. Afr. J. Anim. Sci. 41, 104-115. DOI: 10.4314/sajas.v41i2.71013

Tozer, P.R. \& Huffaker, R.H., 1999. Mathematical equations to describe lactation curves of Holstein-Friesian cows in New South Wales. Aust. J. Agric. Res. 50, 431-440. DOI:10.1071/A98064

White, I.M.S., Thompson, R. \& Brotherstone, S., 1999. Genetic and environmental smoothing of lactation curves with cubic splines. J. Dairy Sci. 82, 632-638. https://doi.org/10.3168/jds.S0022-0302(99)75277-X

Wilmink, J.B.M., 1987. Adjustment of test-day milk, fat and protein yield for age, season and stage of lactation. Livest. Prod. Sci. 16, 335-348. https://doi.org/10.1016/0301-6226(87)90003-0

Wood, P.D.P., 1967. Algebraic model of the lactation curve in cattle. Nature 216, 164-165. https://doi.org/10.1038/216164a0 